\title{
Both Ketamine and NBQX Attenuate Alcohol-Withdrawal Induced Depression in Male Rats
}

\author{
Bruk Getachew and Yousef Tizabi* \\ Department of Pharmacology, Howard University College of Medicine, Washington, DC, USA \\ Address correspondence to Yousef Tizabi,ytizabi@howard.edu
}

Received 11 November 2018; Revised 31 January 2019; Accepted 07 February 2019

Copyright $(2019$ Yousef Tizabi, et al. This is an open access article distributed under the terms of the Creative Commons Attribution License, which permits unrestricted use, distribution, and reproduction in any medium, provided the original work is properly cited.

\begin{abstract}
The co-morbidity between heavy drinking and depression can negatively influence successful cessation of alcohol use. Since ketamine, a glutamatergic NMDA receptor antagonist, has shown promise as a quick-acting antidepressant, we studied its effects specifically on alcohol withdrawal-induced depression. We also evaluated the effects of NBQX an AMPA/kainate receptor antagonist, because some of the effects of ketamine are proposed to be indirectly mediated through these receptors. Adult male Wistar rats were exposed daily to ethanol via inhalation chambers $4 \mathrm{~h}$ /day for 7 days (blood alcohol concentration $=160 \mathrm{mg} \%$ ), followed by daily intraperitoneal injections of ketamine $(2.5 \mathrm{mg} / \mathrm{kg}), \mathrm{NBQX}(5 \mathrm{mg} / \mathrm{kg})$, alone or in combination. Eighteen hours later, open field locomotor activity (OFLA) followed by forced swim test (FST) were performed. The animals were sacrificed 2 $\mathrm{h}$ later for evaluation of brain-derived neurotrophic factor (BDNF) in the hippocampus. Alcohol withdrawal did not affect OFLA, but caused an increase in immobility in FST, suggesting induction of "depressivelike" helplessness. Both ketamine and NBQX normalized the swimming score in FST. The combination of the two drugs, however, cancelled each other's effect. Parallel to these behavioral observations, both ketamine and NBQX normalized the reduction in hippocampal BDNF caused by alcohol withdrawal. Here also, the combination of the two drugs cancelled each other's effect. These results suggest that either NMDA or AMPA/kainate receptor antagonists, acting at least partially through hippocampal BDNF, may be of therapeutic potential in alcohol use disorder.
\end{abstract}

Keywords: alcohol use disorder, depressive behavior, BDNF, hippocampus, glutamate receptors, NMDA antagonist, AMPA antagonist, kainate antagonist

\begin{abstract}
Abbreviations: $\quad$ AMPA: $\quad \alpha$-amino-3-hydroxy-5-methyl-4isoxazolepropionic acid; AUD: Alcohol Use Disorder; BDNF: Brain Derived Neurotrophic Factor; BAC: Blood Alcohol Concentration; EtOH: Ethanol, NBQX: 2,3-dihydroxy-6-nitro-7-sulfamoylbenzo(F) quinoxaline; FST: Forced Swim Test; KET: Ketamine; NMDA: N-methyl D-aspartate; OFLA: Open Field Locomotor Activity
\end{abstract}

\section{Introduction}

Epidemiological studies indicate a strong positive association between heavy drinking (i.e., alcoholism) and depression $[1,2,3]$. Treating the depression that is associated with alcoholism could be a key in improving the cessation rate. However, current antidepressants (e.g., serotonin reuptake inhibitors: SSRIs) can take several weeks to become effective. A major reason for this delay might be the fact that the neurotrophic effects of antidepressants, which are considered critical in reversing the symptoms of depression, may require such a time frame to be manifested $[4,5,6]$. Moreover, most anti-depressants may not be as effective during alcohol use [2,7]. Therefore, novel and quick acting antidepressants to specifically treat alcohol-related depression are urgently needed. Ketamine, an N-methyl D-aspartate (NMDA) antagonist, has been shown to demonstrate rapid and sustained antidepressant effects in both preclinical as well as clinical studies [8-11]. It has also been shown to cause increases in central neurotrophic markers including hippocampal brain-derived neurotrophic factor (BDNF) [9,12,13]. In addition, it enhances the function of postsynaptic AMPA (2-amino-3-(5-methyl-3-oxo-1,2- oxazol-4-yl) propionic acid) receptors $[9,14,15,16]$ and alters AMPA/ NMDA receptor ratio [17], suggesting that AMPA receptors are important in ketamine's antidepressant actions. Interestingly, NBQX (2,3-dihydroxy-6nitro-7-sulfamoylbenzo(F)quinoxaline), an AMPA/ kainate receptor antagonist can block ketamine's antidepressant effects $[14,15,18]$. In this study, our aims were to 1 . determine whether ketamine may block alcohol withdrawal-induced depression, 2. whether the antidepressant effects of ketamine may be blocked by NBQX, and 3. whether hippocampal BDNF may play a role in alcohol withdrawal-induced depression and/ or ketamine's effect. Our results indicate effectiveness of both ketamine and NBQX in blocking alcohol withdrawal-induced depression and suggest a role for hippocampal BDNF in their action. 


\section{Materials and Methods}

\subsection{Animals}

Adult male Wistar rats (8-10-week-old) purchased from Envigo, previously Harlan (Indianapolis, IN, USA) were used throughout the study. Animals were housed in groups of four in standard polypropylene shoebox cages $(42 \times 20.5 \times 20 \mathrm{~cm})$ on hardwood chip bedding (alphadry) in a designated vivarium room. Access to food (Harlan Tek Lab) and water was ad libitum. The room was maintained at $24-26^{\circ} \mathrm{C}$ at $51-66 \%$ relative humidity, on a $12 \mathrm{~h}$ reversed light/dark cycle (lights on at 1900 h). The reversal of light cycle was to allow convenient measurement of behavior in active (dark) phase. In order to acclimate the subjects to the housing conditions, animals arrived at least one week prior to initiation of any experiment. During this period, they were gentled once daily in order to minimize any stress effects that might result from routine handling. All behavioral tests were carried out in the early portion of dark phase between 09:00 AM and 12:00 PM using a red light as source of illumination. All experiments were carried out in accordance with NIH guidelines and approved by the Institutional Animal Care and Use Committee [19].

\subsection{Vapor ethanol (EtOH) exposure and drug treatment}

Inhalation chambers (La Jolla Alcohol Research Inc., La Jolla, CA, USA) were used to expose the animals to EtOH (4 hours daily for 7 days). Briefly, 95\% EtOH was pumped at regulated rate from 5-gallon reservoir via a peristaltic pump to a $5000 \mathrm{ml}$ Erlenmeyer vacuum flask that was kept on a warming tray $\left(52^{\circ} \mathrm{C}\right)$. EtOH was then volatilized and mixed with pressurized air. The flow of this mixture was controlled by a pressure gauge as it was delivered to individual chambers. The parameters used in EtOH vapor exposure were: air pressure $\approx 5$ psi, airflow rate $\approx 16-20$ liter $/ \mathrm{min}$ and $\mathrm{EtOH}$ flow rate $=60 \mathrm{ml} / \mathrm{hr}$. The control group received only air via exactly similar system. The inhalation chamber has the advantage of avoiding the stress of daily injection, easily achieving and maintaining the targeted blood alcohol concentration (BAC) vs the drinking paradigm as the animals in each chamber exhibit very similar BAC and the variability in the EtOH concentration between similarly controlled chambers is minimal $[20,21,22]$.

USP 200 proof ethyl alcohol was purchased from VWR Scientific Products (Bridgeport, New Jersey, USA) and was diluted down $(95 \% \mathrm{v} / \mathrm{v})$ with distilled water. Ketamine $\mathrm{HCl}$ was purchased from Henry Schein (Melville, NY, USA). Ketamine (KET) solution was prepared by diluting a ready-made preparation (10 $\mathrm{mg}$ in $1 \mathrm{ml}$ ) with saline to obtain concentration of $2.5 \mathrm{mg}$ in $1 \mathrm{ml}$. NBQX was purchased from Alomone Labs (Jerusalem, Israel) and dissolved in saline to obtain a concentration of $5 \mathrm{mg}$ in $1 \mathrm{ml}$. Drugs were injected intraperitoneally (i.p.) in a volume of $1 \mathrm{ml} / \mathrm{kg}$ immediately after removal from the vapor chamber.
Control animals were injected with the same volume of physiological saline. To verify the "depressogenic" effect of alcohol, a separate control group was exposed to air in an exact set up followed by saline injection only. Thus, five groups of animals (8 rats/group) consisting of: Air-Saline, Alcohol-Saline, Ketamine-Alcohol, NBQX-Alcohol and (Ketamine+NBQX)-Alcohol were utilized. For combination studies, NBQX was given 15 min prior to ketamine and the control group received 2 saline injections in the same order. The dosing of drugs was chosen based on works of others as well as ours that have been reported in the literature $[9,23,24]$. This dose selection minimized the number of animals to be utilized as we had 4 treatment groups plus the appropriate control groups.

\subsection{Blood alcohol determination}

To determine the concentration of alcohol in the blood (BAC) at various time points, a separate group of Wistar rats were exposed to the chambers under identical conditions. Blood was sampled by tail bleed technique every three days immediately after the end of daily EtOH exposure [22]. Briefly, tail blood $(0.4 \mathrm{ml})$ was collected in tubes coated with $0.2 \mathrm{M}$ ethylenediaminetetraacetic acid (EDTA) (Sigma-Aldrich Co., St. Louis, MO, USA) and centrifuged for $5 \mathrm{~min}$ at $1,500 \mathrm{~g}$ at $4^{\circ} \mathrm{C}$. The plasma was extracted, and BAC was assayed by injecting $5 \mu \mathrm{L}$ plasma into GM7 Micro-Stat Analyzer (Analox Instruments Ltd., Lunenburg, MA, USA).

\subsection{Behavioral evaluations}

\subsubsection{Open Field Locomotor Activity (OFLA) Monitoring}

On day 8 , approximately $18 \mathrm{~h}$ after the last alcohol exposure and drug treatment, animals were tested in an open-field activity monitoring cage $(27 \times 27 \times 20.3 \mathrm{~cm}$, Med Associates, Inc., St. Albans, VT) for 5 min where ambulatory counts representing the number of infrared beam interruptions were recorded [22]. This behavior was assessed to determine if drug treatment affected general locomotor behavior, which might impinge on forced swim test immobility assessment [9, 22]. It is important to note that no drug was on board during the behavioral tests.

\subsubsection{Forced Swim Test (FST)}

Immediately following the open field activity test each animal was evaluated for its behavior (immobility) in the forced swim test (FST) $[9,22,25]$. Briefly, each rat was placed in a Pyrex cylinder pool measuring $17 \mathrm{~cm}$ in diameter and $60 \mathrm{~cm}$ in height for $5 \mathrm{~min}$. The cylinder was filled with $30 \mathrm{~cm}$ water $\left(25 \pm 1{ }^{\circ} \mathrm{C}\right)$ to ensure that animals could not touch the bottom of the container with their hind paws or their tails. The FST activity was video recorded for subsequent analysis. The rat was removed after $5 \mathrm{~min}$, dried, and placed in its home cage. A time sampling scoring technique was used whereby 
the predominant behavior in each 5-s period of the 300$\mathrm{s}$ test was recorded. Inactivity (immobility) and activity (swimming) were distinguished as mutually exclusive behavioral states. Swimming behavior was defined as movement (usually horizontal) throughout the cylinder. Immobility was defined when no additional activity was observed other than that required to keep the rat's head above the water $[9,22,25]$.

\subsubsection{Tissue collection}

Animals were sacrificed by decapitation, approximately $2 \mathrm{~h}$ after the last behavioral test (i.e., FST). Brains were quickly removed, frozen on dry ice and stored at $-80^{\circ} \mathrm{C}$ until dissection for BDNF measurement [9]. The hippocampus (bilateral) was dissected as previously described [27].

\subsubsection{Western blot}

This was performed as described in detail previously [9]. Briefly, homogenate of the dissected hippocampus (bilateral) were made in lysis buffer $(10 \mathrm{mM}$ Tris-buffer, $5 \mathrm{mM}$ EDTA, $150 \mathrm{mM} \mathrm{NaCl}, 0.5 \%$ Triton X-100 (v/v) with protease inhibitors (Sigma-Aldrich, St. Louis, MO). The protein concentration in each sample was determined using a BCA protein Assay Kit (Pierce Biotechnology Inc., IL), and equal protein amount (as confirmed by $\beta$-actin) was loaded in each immunoblot. The proteins were separated using 12\% SDS-PAGE gel and transferred onto a nitrocellulose membrane. The membranes were blocked with a blocking reagent $(5 \%$ nonfat milk in TBS buffer) for $1 / 2 \mathrm{~h}$ and incubated at $4{ }^{\circ} \mathrm{C}$ overnight with the primary antibody against $\operatorname{BDNF}(1: 1000$, Santa Cruz Biotechnology Inc., Santa Cruz, CA). The membranes were washed with TBST (TBS buffer with 1\% Tween-20) and blocked with the blocking reagent. Membranes were then incubated for $1 \mathrm{~h}$ at room temperature in Goat AntiRabbit-HRP conjugated secondary antibody (1:3000 in TBS, Bio-Rad Laboratories, CA). The membranes were then washed in the TBST washing solution and then visualized using enhanced chemiluminescent kits (Bio-Rad Laboratories, CA). The intensity of the protein bands on the gel was quantified using ChemiDoc XRS system (Bio-Rad Laboratories, CA).

\subsubsection{Statistical Analysis}

Statistical differences between treatment groups were determined by one-way analysis of variance (ANOVA) followed by post-hoc Newman-Keuls Multiple comparison test to determine which groups differed. Significant difference was set a priori at $p<0.05$. Data were analyzed using Graphpad Prism 3 (Graphpad Software, Inc., San Diego, CA, USA).

\section{Results}

3.1. BAC and the effects of alcohol withdrawal on OFLA and FST

Daily BAC fluctuated between 150-168 mg\% (160.2 \pm 5.8 $\mathrm{mg} \%$ mean $\pm \mathrm{SEM}$ ) for all time measurements. This BAC is equivalent to relatively high alcohol consumption in humans, which is twice the legal limit allowed in most states $[22,25,26]$.

Withdrawal from alcohol caused an increase in immobility in FST (Fig 1A). Thus, there was approximately 2.4fold increase [control $=18 \pm 3, A l c=44 \pm 6, F(4,35)=32.1$, $\mathrm{p}<0.01)$ ] in immobility in FST following withdrawal from 7 days of alcohol exposure in Wistar rats Fig 1A, columns 1 and 2). Withdrawal from alcohol did not affect OFLA (Fig 1B, columns 1 and 2).

3.2. Effects of ketamine (KET), NBQX and their combination on alcohol-induced behavioral changes

Both ketamine and NBQX treatment reversed alcoholinduced increases in immobility in Wistar rats. Thus, following daily administration of KET $(2.5 \mathrm{mg} / \mathrm{kg})$ and NBQX $(5.0 \mathrm{mg} / \mathrm{kg})$ the immobility scores were back to the original levels $(\mathrm{KET}=16 \pm 3, \mathrm{NBQX}=19 \pm 4)$, Fig 1B (columns 3 and 4). The combination of KET and NBQX, however, did not cause any significant reduction in immobility in the FST (42 \pm 7$)$, suggesting cancellation of each other's effect (Fig 1B, columns 3-5). Neither drug or their combination affected the OFLA (Fig 1B columns 3-5), indicating that the observed effects in the FST were not due to motor impairment. In addition, no difference between single and double saline injection was noted.

3.3. Effects of alcohol withdrawal on Hippocampal BDNF

Figures 2 depict the effects of withdrawal from 7 days EtOH exposure on hippocampal BDNF levels. As seen in columns 1 and 2, alcohol withdrawal resulted in a significant decrease (approximately 35\%, F(4,35)=9.03 $\mathrm{p}<0.05$ ) in hippocampal BDNF.

3.4. Effects of ketamine (KET), NBQX and their combination on alcohol-induced BDNF changes

Figures 2 shows that both ketamine $(2.5 \mathrm{mg} / \mathrm{kg})$ and NBQX $(5 \mathrm{mg} / \mathrm{kg})$ administered daily reversed alcoholinduced decreases in hippocampal BDNF as the levels were not different from the control (columns 3 and 4). The combination of the two drugs, however, did not affect the BDNF level (column 5). In addition, no difference between single and double saline injection was noted.

\section{Discussion}

The results of the current study provide evidence of effectiveness of both ketamine and NBQX in preventing depressive-like behavior following alcohol withdrawal in male Wistar rats. Ketamine, an NMDA receptor antagonist has been shown to exert antidepressant effects in various models of depression as well as in a number of clinical trials [8-11]. Indeed, (S)-ketamine (esketamine) is in approval process by FDA as a fastacting antidepressant with particular application in treatment-resistant depression and suicidal ideation [28]. Thus, our results in agreement with those of others $[29,30,31]$ suggest potential usefulness of this drug 


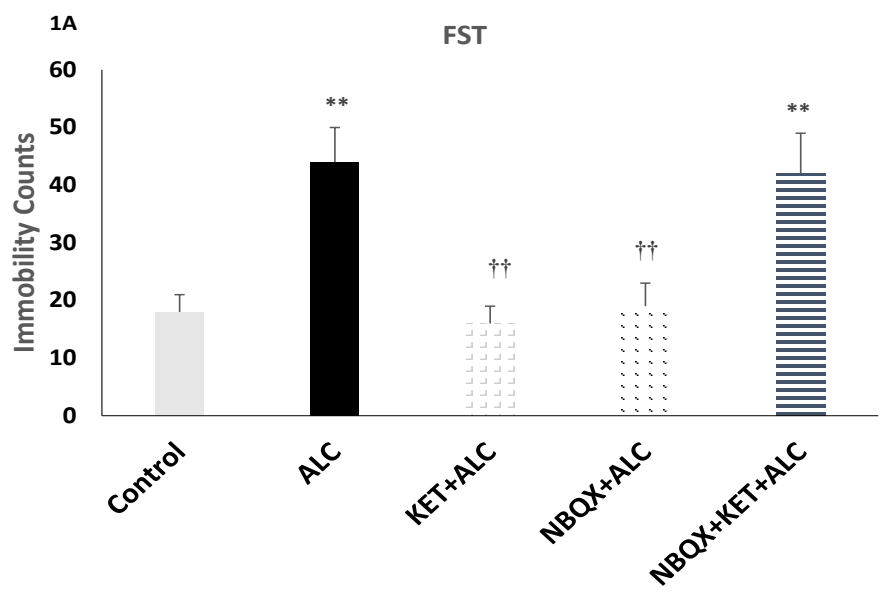

$1 \mathrm{~B}$ Open Field

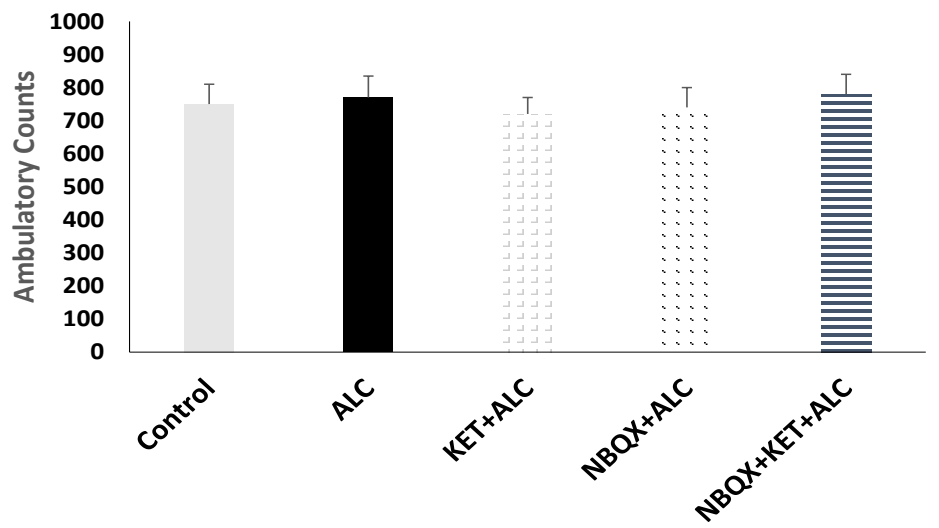

Figure 1: Effects of withdrawal from chronic alcohol, administration of ketamine (KET), NBQX and their combination on immobility scores in the forced swim test (Fig 1A) and on open field locomotor activity (Fig 1B) in male Wistar rats. Animals were exposed to EtOH vapor daily for $4 \mathrm{~h}$ such that an average of $\mathrm{BAC}$ of $160 \mathrm{mg} \%$ was achieved daily. Controls were exposed to air only. Following EtOH exposure the animals were treated daily with ketamine $(2.5 \mathrm{mg} / \mathrm{kg}), \mathrm{NBQX}(5 \mathrm{mg} / \mathrm{kg})$ or their combination and evaluated for their behavior approximately $18 \mathrm{~h}$ later. Values are mean $\pm \mathrm{SEM}$ (n=8/group). ${ }^{* *} \mathrm{p}<0.01$ compared to control. ${ }^{~} \mathrm{p} p<0.01$ compared to alcohol group.

\section{BDNF \\ B-Actin}

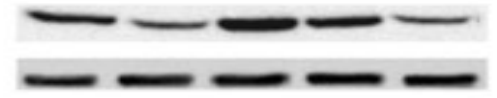

Hippocampal BDNF

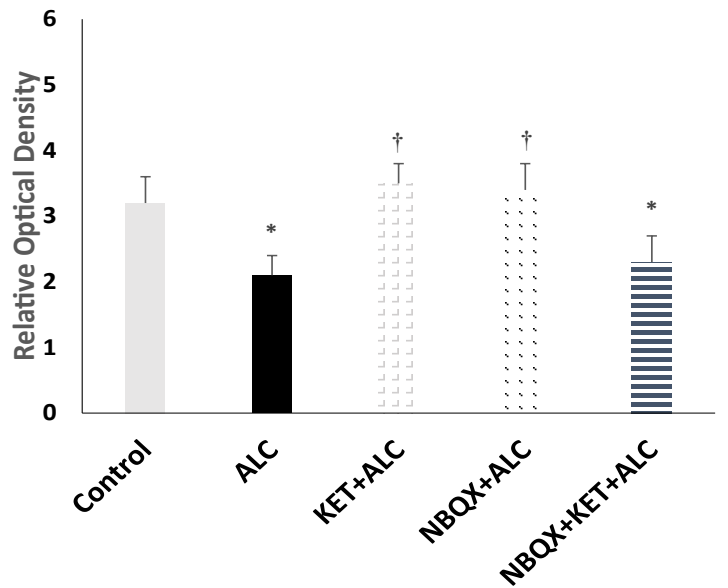

Figure 2: Effects of withdrawal from chronic alcohol, administration of ketamine (KET), NBQX and their combination on BDNF levels in the hippocampus of male Wistar rats. Animals were exposed to EtOH vapor daily for $4 \mathrm{~h}$ such that an average of BAC of $160 \mathrm{mg} \%$ was achieved daily. Controls were exposed to air only. Following alcohol exposure, the animals were treated daily with ketamine ( $2.5 \mathrm{mg} / \mathrm{kg}), \mathrm{NBQX}$ ( $5 \mathrm{mg} / \mathrm{kg})$ or their combination and evaluated for their behavior approximately $18 \mathrm{~h}$ later. $2 \mathrm{~h}$ after the behavioral tests the animals were sacrificed, and their brains removed for later dissection and evaluation of BDNF by Western blot. Representative immunoblot is included. Values are mean $\pm \mathrm{SEM}$ ( $\mathrm{n}=8 / \mathrm{group}$ ). ${ }^{*} \mathrm{p}<0.05$ compared to control. ${ }^{\dagger} \mathrm{p}<0.05$ compared to alcohol group. 
specifically in depression associated with alcoholism. Such intervention may also reduce the risk of alcohol relapse since depression that is associated with alcohol withdrawal may be an important contributor to alcohol relapse [32,33].

An interesting, yet surprising finding in our studies was that NBQX, an AMAP/kainate glutamatergic receptor antagonist, was also effective in blocking alcohol withdrawal-induced depression in our model. This was unexpected because it was previously shown that NBQX is capable of blocking the antidepressant effects of ketamine in mice $[14,18]$. Although neither Maeng et al (2008) nor Koike et al (2011) evaluated the effect of NBQX alone, no potential antidepressant effect of NBQX has been indicated in the literature [14,18]. Thus, our study for the first time indicates potential antidepressantlike effects of NBQX, at least in alcohol withdrawal model. Yet, when NBQX and ketamine were combined, no antidepressant effect was observed. This, in line with previous findings, does suggest antagonism of ketamine's antidepressant effect by NBQX $[14,15,18]$.

It is important to recognize that NBQX acts as an antagonist at both AMPA and kainate receptors [34,35]. Whereas the role of AMPA receptors in depression are firmly established the role of kainate receptors in mood regulation are far from clear. Thus, a number of studies indicate up-regulation of AMPA receptors by ketamine [17] and antidepressant effects of various AMPA-kines (AMPA mimicking or AMPA-modulating compounds) as well as AMPA itself in various animal models of depression $[9,14,15,36]$. These and few more recent studies suggest that stimulation of central AMPA receptors may lead to an antidepressant and other beneficial behavioral effect and that some of ketamine's effect may be indirectly mediated through these receptors $[16,37]$. However, kainate receptors, although present in hippocampus and implicated in synaptic plasticity [38,39], have not been implicated in mood regulation. Hence, it may be suggested that AMPA receptor antagonism of NBQX is likely responsible for the antagonism of the antidepressant effects of ketamine, whereas its antagonism of kainate receptor may be responsible for its own antidepressant effect in our model. In this regard, it would be of considerable clinical significance to see whether kainate only antagonists may have general or specific antidepressant effects. Moreover, in light of a recent study implicating the hippocampal ionotropic glutamate receptors in cognitive decline associated with depression [39], it would be prudent to also access the effects of the novel glutamate receptor modulators on cognitive functions associated with depression and/or AUD.

Our results on BDNF measurements suggest that the central mediator of the antidepressant effects of both ketamine and NBQX appears to involve the hippocampal BDNF. This contention is based on the finding that the levels of BDNF were reduced in the hippocampus following withdrawal from daily alcohol exposure and that both ketamine and NBQX reversed this decrease. Moreover, parallel to the observation of the antidepressant effects, when NBQX and ketamine were combined, the levels of BDNF in the hippocampus were not altered. This finding is in agreement with numerous studies implicating a role for hippocampal BDNF in depression and antidepressant effects of many drugs including ketamine $[3,9,41,42]$.

The observed effectiveness of ketamine and NBQX in countering alcohol withdrawal-induced depression in this study, together with recent findings of the effectiveness of both of these drugs in reducing alcohol intake [22,23] may offer unique intervention opportunity in alcohol use disorder (AUD). Thus, it was demonstrated that ketamine may reduce alcohol intake in alcohol preferring rats [23] and that both NBQX and ketamine may reduce alcohol intake in a drinking-in-the dark paradigm [22]. It should be noted that ketamine effect was shown in both male and female rats, whereas NBQX was studied in male Wistar rats only. Thus, future studies of potential sex differences in response to the behavioral effects of both these drugs need to be addressed [43, 44]. In this regard it is of relevance to note that a recent study did not detect any sex difference in acute antidepressant effect of (R)-ketamine in an inflammation model [45]. However, ketamine per se, might not be most suitable in alcohol intake intervention, as it may pose abuse potential and other adverse effects of its own [46,47]. Nonetheless, the current findings do emphasize the importance of the glutamatergic system in AUD and potential exploitation of the system, particularly its ionotropic receptors in this devastating disorder [48-50]. In this regard, it is of interest to note that some metabolites of ketamine, e.g. $(2 R, 6 R)$-hydroxynorketamine, might be suitable candidate drugs as their side effects appear to be less than ketamine [51,52].

In summary the findings of this study suggest usefulness of NMDA or kainate antagonists in depression associated with alcohol withdrawal and possible prevention of relapse to alcohol. Moreover, a role for hippocampal BDNF in the actions of these drugs is indicated.

\section{Acknowledgement}

This work was supported by National Institutes of Health (National Institute on Alcohol Abuse and Alcoholism NIH/NIAAA R03AA022479). The Authors wish to thank Dr. Daniel Asher for his help in EtOH exposure procedure and behavioral testing.

\section{References}

1. N. S. Miller, D. Klamen, N. G. Hoffman, and J. A. Flaherty, Prevalence of depression and alcohol and other drug dependence in addictions treatment populations, J Psychoactive Drugs, 28 (1996), 111-124.

2. R. Agabio, E. Trogu, and P. P. Pani, Antidepressant for the treatment of people with co-ocurring depression and alcohol dependence, Cochrane Database Syst Rev, 4 (2018), CD008581. 
3. Y. Tizabi, B. Getachew, C. L. Ferguson, A. B. Csoka, K. M Thompson, A. Gomez-Paz, et al. Low Vs. High Alcohol: Central Benefits Vs. Detriments. Neurotox Res, 2018.

4. R. S. Duman, J. Malberg, S. Nakagawa, and C. D'Sa, Neuronal plasticity and survival in mood disorders, Biol Psychiatry, 48(2000), 732-739.

5. M. Banasr, J. M. Dwyer, R. S. Duman, Cell atrophy and loss in depression: Reversal by antidepressant treatment, Current Opinion in Cell Biology, 23 (2001), 730-737.

6. M. J. F. Levy, F. Boulle, H. W. Steinbusch, D. L. A. van den Hove, G. Kenis, and L. Lanfumey, Neurotropic factors and neuroplasticity pathways in the pathophysiology and treatment of depression, Psychopharmacology (Berl) 235 (2018), 2195-2220.

7. P. Chan, K. Yomen, J. Turcios, and M. Richman, Prescription for antidepressant in reducing future alcohol-related readmission in patients suffering from depression and alcohol use disorder: a retrospective medical record review, Substance Abuse Treatment, Prevention, and Policy, 10 (2015), 48.

8. C. A. Zarate Jr, J. B. Singh, P. J. Carlson, N. E. Brutsche, R. Ameli, D. A. Luckenbaugh, et al. A randomized trial of an $N$-methyl-Daspartate antagonist in treatment-resistant major depression, Arch Gen Psychiatry, 63(2006), 856-864.

9. L. Akinfiresoye, and Y. Tizabi, Antidepressant effects of AMPA and ketamine combination: role of hippocampal BDNF, synapsin, and mTOR, Psychopharmacology, 2013.

10. A. Pałucha-Poniewiera, The role of glutamatergic modulation in the mechanism of action of ketamine, a prototype rapid-acting antidepressant drug, Pharmacol Rep, 70(2018), 837-846.

11. J. L. Reed, A. C. Nugent, M. L. Furey, J. E. Szczepanik, J. W. Evans, and C. A. Jr Zarate, Ketamine normalizes brain activity during emationally valenced attentional processing in depression, Neuroimage Clin, 20(2018), 92-101.

12. Y. Tizabi, Duality of antidepressants and neuroprotectants, Neurotox Res, 30(2016), 1-13.

13. D. M. Gerhard, and R. S. Duman, Rapid-Acting Antidepressants: Mechanistic Insights and Future Directions. Curr Behav Neurosci Rep, 5(2018), 36-47.

14. S. Maeng, C. A. Zarate Jr, J. Du, R. J. Schloesser, J. McCammon, $\mathrm{G}$. Chen, et al. Cellular mechanisms underlying the antidepressant effects of ketamine: role of $\alpha$-amino-3-hydroxy-5-methylisoxazole4-propionic acid receptors, Biol Psychiatry, 63(2008), 349-352.

15. W. Zhou, N. Wang, C. Yang, X. M. Li, Z. Q. Zhou, and J. J. Yang, Ketamine-induced antidepressant effects are associated with $A M P A$ receptors-mediated upregulation of $m T O R$ and BDNF in rat hippocampus and prefrontal cortex, Eur Psychiatry, 29 (2014), 419-23.

16. N. Llamosas, L. Perez-Caballero, E. Berrocoso, C. BruzosCidon, L. Ugedo, and M. Torrecilla, Ketamine promotes rapid and transient activation of AMPA receptor-mediated synaptic transmission in the dorsal raphe nucleus, Prog Neuropsychopharmacol Biol Psychiatry, 88 (2018), 243-252.

17. Y. Tizabi, B. H. Bhatti, K. F. Manaye, J. R. Das, L. Akinfiresoye, Antidepressant-like effects of low ketamine dose is associated with increased hippocampal AMPA/NMDA receptor density ratio in female Wistar-Kyoto rats, Neuroscience, 213 (2012), 2-80.

18. H. Koike, M. Ijima, S. Chaki, Involvement of AMPA receptor in both the rapid and sustained antidepressant-like effects of ketamine in animal models of depression, Behav Brain Res, 2224 (2011), 107-111.

19. Research Institute for Laboratory Animal Research (2011) Guide for the Care and Use of Laboratory Animals. 8th ed. The National Academies Press, Washington, D.C.
20. C. L. Kliethermes, K. Cronise, and J. C. Crabbe, Anxiety-like behavior in mice in two apparatuses during withdrawal from chronic ethanol vapor inhalation, Alcohol Clin Exp Res, 28 (2004), 1012-1019.

21. A. L. Lee, W. O. Ogle, and R. M. Sapolsky, Stress and depression: Possible links to neuron death in the hippocampus, Bipolar Disorders, 4 (2002), 17-128.

22. B. Getachew, S. R. Hauser, A. B. Csoka, R. E. Taylor, and Y. Tizabi, Role of cortical alpha-2 adrenoceptors in alcohol withdrawal-induced depression and tricyclic antidepressants, Drug Alcohol Depend, 175 (2017), 133-139.

23. J. Ruda-Kucerova, Z. Babinska, M. Luptak, B. Getachew, and Y. Tizabi, Both ketamine and NBQX attenuate alcohol drinking in male Wistar rats, Neurosci Lett, 666 (2018), 175-180.

24. A. H. Rezvani, E. D. Levin, M. Cauley, B. Getachew, Y. Tizabi, Ketamine Differentially Attenuates Alcohol Intake in Male Versus Female Alcohol Preferring (P) Rats, J Drug Alcohol Res, 2017, 6.

25. B. Getachew, S. R. Hauser, R. E. Taylor, and Y. Tizabi, Alcoholinduced depressive-like behavior is associated with cortical norepinephrine reduction, Pharmacol Biochem Behav, 96 (2010), 395-401.

26. B. Getachew, S. R. Hauser, R. E. Taylor, Y. Tizabi, Desipramine blocks alcohol-induced anxiety-and depressive-like behaviors in two rat strains, Pharmacol Biochem Behav, 91 (2008), 97-103.

27. O. Kalejaiye, B. H. Bhatti, R. E. Taylor, and Y. Tizabi, Nicotine Blocks the Depressogenic Effects of Alcohol: Implications for Drinking-Smoking Co-Morbidity, J Drug Alcohol Res, 2 (2013), 235709.

28. R. S. Duman, Ketamine and rapid-acting antidepressants: a new era in the battle against depression and suicide, F1000 Res, 24 (2018), 7.

29. K. M. Holleran, H. H. Wilson, T. L. Fetterly, R. J. Bluett, S W. Centanni, R. A. Gilfarb, et al. Ketamine and MAG Lipase Inhibitor-Dependent Reversal of Evolving Depressive-Like Behavior During Forced Abstinence From Alcohol Drinking, Neuropsychopharmacology, 41(2016), 2062-2071.

30. O. Vranjkovic, G. Winkler, and D. G. Winder, Ketamine and rapid-acting antidepressants: a new era in the battle against depression and suicide, Neuropsychopharmacology, 43 (2018), 1915-1923.

31. K. M. Holleran, and D. G. Winder, Preclinical voluntary drinking models for alcohol abstinence-induced affective disturbances in mice, Genes Brain Behav, 16 (2017), 8-14.

32. J. Li, S. Kang, R. Fu, L. Wu, W. Wu, H. Liu, et al. Inhibition of AMPA receptor and CaMKII activity in the lateral habenula reduces depressive-like behavior and alcohol intake in rats, Neuropharmacology, 126 (2017), 108-120.

33. K. Schooover, M. C. Burton, S. A. Larson, S. S. and Cha, M. I. Lapid, Depression and alcohol withdrawal syndrome: is antidepressant therapy associated with lower rates of hospital readmission? Ir J Med Sci, 185 (2016), 573-579.

34. M. J. Sheardown, E. O. Nielsen, A. J. Hansen, P. Jacobsen, and T. Honore, 2,3-Dihydroxy-6-nitro-7-sulfamoyl-benzo(F)quinoxaline: a neuroprotectant for cerebral ischemia, Science, 247 (1990), 571-574.

35. J. E. Libbey, T. J. Hanak, D. J. Doty, K. S. Wilcox, and R. S. Fujinami, $N B Q X$, a highly selective competitive antagonist of AMPA and KA ionotropic glutamate receptors, increases seizures and mortality following picornavirus infection, Experimental Neurology, 280 (2016), 89-96.

36. R. Machado-Vieira, L. D. Henter, and C. A. Zarate Jr, New Targets for Rapid Antidepressant Action, Prog Neurobiol, 152 (2017), 21-37. 
37. J. W. Kim, K. Park, R. J. Kang, E. L. T. Gonzales, D. G. Kim, H. A. Oh, et al. Pharmacological modulation of AMPA receptor rescues social impairments in animal models of autism, Neuropsychopharmacology, 2018.

38. M. Carta, S. Fièvre, A. Gorlewicz, and C. Mulle, Kainate receptors in the hippocampus, Eur J Neurosci, 39 (2014), 1835-1844.

39. Z. A. Bortolotto, V. R. Clarke, C. M. Delany, M. C. Parry, I. Smolders, M. Vignes, et al. Kainate receptors are involved in synaptic plasticity, Nature, 402 (1999), 297-301.

40. Y. Yu, J. Weina, Z. Haining, S. Li, Effect of ketamine on LTP and NMDAR EPSC in hippocampus of the chronic social defeat stress mice model of depression, Frontiers in Behavioral Neuroscience, 12 (2018), 229.

41. W. Boonlert, H. Benya-Aphikul, J. Umka Welbat, and R. Rodsiri, Ginseng extract G115 attenuates ethanol-induced depression in mice by increasing brain BDNF levels, Nutrients, 9 (2017).

42. L. L. Hurley, L. Akinfiresoye, O. Kalejaiye, and Y. Tizabi, Antidepressant effects of resveratrol in an animal model of depression, Behav Brain Res, 15 (2014), 1-7.

43. T. L. Bale, and C. N. Epperson, Sex as a biological variable: who, what, when, why, and how, Neuropsychopharmacology, 42 (2017), 386-396.

44. J. B. Becker, and G. F. Koob, Sex Differences in Animal Models: Focus on Addiction, Pharmacol Rev, 68 (2016), 242-263.
45. L. Chang, H. Toki, Y. Qu, Y. Fujita, A. Mizuno-Yasuhira, J. I. Yamaguchi, et al. No Sex-Specific Differences in the Acute Antidepressant Actions of (R)-Ketamine in an Inflammation Model, Int J Neuropsychopharmacol, Oct 21 (2018), 932-937.

46. P. R. Corlett, G. D. Honey, and P. C. Fletcher, Prediction error, ketamine and psychosis: An updated model, J Psychopharmacol, 30 (2016), 1145-1155.

47. Z. Babinska, and J. Ruda-Kucerova, Differential characteristics of ketamine self-administration in the olfactory bulbectomy model of depression in male rats, Exp Clin Psychopharmacol 25 (2017), 84-93.

48. M. S. D'Souza, Glutamatergic transmission in drug reward: implications for drug addiction, Front Neurosci, 9 (2015), 404.

49. P. S. Holmes, R. Spanagel, and J. H. Krystal, Glutamatergic targets for new alcohol medications, Psychopharmacology, 229 (2013), 539-554.

50. P. S. Rao, R. L. Bell, E. A. Engleman, Y. Sari, Targeting glutamate uptake to treat alcohol use disorders, Front Neurosci, 9 (2015), 144.

51. P. Zanos, R. Moaddel, P. J. Morris, P. Georgiou, J. Fischell, G. I. Elmer, et al. NMDAR inhibition-independent antidepressant actions of ketamine metabolites, Nature, 533 (2016), 481-486.

52. F. Freudenberg, T. Celikel, and A. Reif, The role of alpha-amino3-hydroxy-5-methyl-4-isoxazolepropionic acid (AMPA) receptors in depression: central mediators of pathophysiology and antidepressant activity? Neurosci Biobehav Rev, 52 (2015), 193-206. 